January 2011

\title{
The Lived Experience of Discontinuing Hormonal Contraception Among Women in Rural Uganda
}

Joseph Mwizerwa

The Aga Khan University, joseph.mwizerwa@aku.edu

Locsin C. Rozzano

Florida Atlantic University

Follow this and additional works at: http://ecommons.aku.edu/eastafrica_fhs_sonam

Part of the Nursing Commons

\section{Recommended Citation}

Mwizerwa, J., Rozzano, L. C. (2011). The Lived Experience of Discontinuing Hormonal Contraception Among Women in Rural Uganda. International Journal for Human Caring, 15(1), 56-64.

Available at: $\mathrm{http}: / /$ ecommons.aku.edu/eastafrica_fhs_sonam/66 


\title{
The Lived Experience of Discontinuing Hormonal Contraception Among Women in Rural Uganda
}

\author{
Joseph Mwizerwa, BSN, MSN \\ Department of Nursing \\ Mbarara University of Science and Technology \\ Droesbeke Award Recipient
}

\author{
Rozzano C. Locsin, RN, PhD, FAAN \\ John F. Wymer Distinguished Professor of Nursing \\ Florida Atlantic University \\ Christine E. Lynn College of Nursing
}

\begin{abstract}
The purpose of the study was to describe the experience of discontinuing hormonal contraceptive use among women in rural Uganda. A significant number of women in Uganda discontinue hormonal contraception even though such method has been effective. Consequently, these women have unprotected sex, although not wanting to conceive. Narrative descriptions of the experiences by eight women were analyzed using content analysis. The findings describe the experience as Frustration and Helplessness, Living in Fear of Uncertainty, Ingenuity of using other methods of contraception, thus fostering the Accomplishments of being a wife, mother, and woman. Implications for nursing practice, research, and education are described.
\end{abstract}

Key Words: Contraceptive behavior, contraceptive usage, lived experience, hormonal contraception, family planning services

\section{Introduction}

Contraception is a term used to describe the process of preventing pregnancy and is commonly referred to as birth control or family planning. Its purpose is to prevent conception and to conceive only when contraception is desired. It is an important nursing phenomenon requiring study as it influences nursing and its practice.

Women have practiced contraception for many years throughout history. Various civilizations and cultures have used a variety of contraception methods to acquire and maintain desired family size, especially to a level within their social and economic capabilities (Uganda Bureau of Statistics [UBOS], 2001).

There are several methods of contraception, some of which are created for women and others for men. Some methods are considered permanent while others are reversible. The majority of birth control methods can be classified and fall into one of the following two major consequential categories: barrier contraception or hormonal contraception. The majority of women who desire birth control opt for the hormonal methods because they are highly effective (Ott, Adler, Millstein, Tschann, \& Ellen, 2002), the effective rates being as high as $98 \%$ for most of the methods. However, hormonal contraception has been associated with challenges that have led to its discontinuation.

\section{Background}

While working in a family planning service delivery center in one of the rural districts of western Uganda between 2001 and 2003, the lead researcher noticed that many women discontinued hormonal contraception even when effective in preventing preg- nancies. These women continued to have unprotected sex although not desiring to conceive.

Most women who discontinue hormonal contraception do so mainly because of side effects. The majority of these women choose to use less effective methods such as withdrawal (coitus interuptus), which has high failure rates. The failure rate for the withdrawal method is estimated to be $30 \%$. This means that out of every ten women who rely on it, three are likely to conceive. Essentially, the number of women discontinuing hormonal contraception is increasing (Ali \& Cleland, 1995). Given that women who choose to discontinue hormonal contraception are increasing and, as a phenomenon that is consistent with a nursing focus, describing their experience is crucial to pursuing responsive and informed nursing practice for this often-oppressed group.

\section{Significance}

Describing the lived experience of discontinuing hormonal contraception among women in rural Uganda will inform the practice of nursing of persons during their reproductive years. Understanding the nature of their decision making regarding hormonal contraception is critical to a successful reproductive health program. It will also assist contraception service 
providers to understand the experience of rural women who discontinue hormonal contraception with the ultimate intention of enhancing their opportunities toward selfhelp and empowerment. Furthermore, this study also recognizes the role that nurses and midwives play as uniquely situated to assist women with birth control decisions as they counsel, provide education, and prescribe methods (Noone, 2004).

\section{Literature Review}

According to $\mathrm{Wu}$, Wang, Rauyajin, and Good's study (2002), women in developing countries are discontinuing contraception. They found that approximately $75 \%$ of the respondents in their study had not used contraception methods during the past 12 months and that only $13 \%$ insisted on its use. This indicated that the discontinuation behavior was high. A look at the discontinuation rates in several developing countries that have large numbers of contraceptive users suggested an ever-increasing hormonal contraception discontinuation trend (Ali \& Cleland, 1995). The cases of Morocco, Tunisia, Egypt, Ecuador, Indonesia, and Thailand show a general trend wherein $33.3 \%$ of couples stop the use of a method within a year and roughly $50 \%$ stop in 2 years. Users of the intrauterine device (IUD) method have a lesser probability of discontinuation, with some $80 \%$ to $90 \%$ still using after 1 year and $65 \%$ to $80 \%$ still using after 2 years. The reasons for discontinuation vary. Consequently, Rosenberg, Burnhill, Waugh, Grimes, and Hillard (1998) discovered that $25 \%$ to $50 \%$ of women discontinued the use of contraceptive pills after only 1 year and, yet, strongly expressed that they did not want to conceive. This study did not explore if the women went on to use other methods. Also, Affandi et al. (1987), looking at a 5-year experience with Norplant (a hormonal progestogen implant type of birth control), found discontinuation rates of $40 \%, 58 \%$, and $71 \%$, respectively at 3 years of use.

The trends in developed countries were not much different. Trussell and Vaughan's (1999) study involving about 7,000 women reported that probabilities of discontinuation within 6 months is $31 \%$, within 12 months, $44 \%$, and within 24 months, $61 \%$. Tabulation of the total lifetime methodrelated contraceptive discontinuation rate was found to be 9.5 . This means that the typical woman who uses reversible methods of contraception continuously (except for the time spent pregnant following a contraceptive failure) from age 15 to age 45 will discontinue use for a method-related reason 9.5 times.

Westfall, Main, and Barnard (1996), while studying continuation rates among injectable contraceptive users, found that of the 5,178 women who received an initial injection, only $57 \%$ returned for the second administration and only $36 \%$ went on to receive a third. This indicated a very high discontinuation rate, yet the injection is one of the highly preferred and highly effective contraception methods. Moreover, Jarman, Kovacs, and Westcott's (1990) findings were similar and found a 1-year discontinuation rate of $61 \%$ from a survey involving 70 clients from the Family Planning Association of Victoria's Richmond Clinic in Australia.

If one focuses on discontinuation of all methods combined, a surprisingly consistent pattern emerges, despite the diversity of settings. This therefore paints a worrying picture if couples are to enjoy a comfortable and quality sexual and reproductive health life.

A look at the reasons for the high hormonal contraception discontinuation rates indicates an association with menstrual side effects. For a method-related reason (side effects), discontinuing use of a reversible contraceptive is very common (Trussell \& Vaughan, 1999). Besides the methodrelated side effects, there are socio-cultural factors associated with discontinuation. Darroch, Landry, and Oslak (1999) found that a male partner's opinion toward contraceptive methods is associated with contra- ception discontinuation among most women and adolescents (although the study talks more about the factor of age rather than contraception).

According to the Uganda Delivery of Improved Services for Health (DISH, 2001), a Ugandan non-government organization, women who have not yet reached or exceeded their ideal family size are most likely to discontinue contraception even when they are not consciously discontinuing for the purpose of conception. The overall risks of discontinuation depend on whether the client will choose another effective method.

\section{Theoretical Framework}

Orem's self-care deficit nursing theory (Taylor, 2006) was used to describe and explain the lived experience of discontinuing hormonal contraception among women in rural Uganda. In her theory, Orem identified basic conditioning factors that she defined as "conditions or events in a time place matrix that affect the value of person's abilities to care for themselves" (Orem, 1995). The second proposition of the basic conditioning factors stated that the "individuals' abilities to engage in self-care are conditioned by age, developmental state, life experiences, socio-cultural orientation, health, and available resources" (Orem, 1995, p. 175). In this study, the "life experiences" of the challenges presented by hormonal contraceptives was utilized as conditioning factors to discontinuation. These data were consequently used to describe the lived experience of discontinuing hormonal contraception among women in rural Uganda.

\section{Methods}

\section{Research Design}

The study employed a qualitative descriptive design and utilized the phenomenological approach to analyze the data. The design was chosen because it provided a procedure for generating data for the purpose of describing the experience of 
women in rural Uganda who discontinued hormonal contraceptive use.

\section{Study Setting}

The study was conducted in the rural villages of the Mbarara District, which is located 286 kilometers from Kampala, the capital of the Republic of Uganda. It has an estimated population of 1.8 million (UBOS, 2001). The district has a low "modern contraceptive use" rate of $27 \%$ (UBOS, 2001) and unknown discontinuation rates, although the latter seems to be high as exhibited by high birth rates.

\section{Description of Participants}

Using purposive sampling to select participants for the study, identification of participants was done by word of mouth, often verifying their qualifications with the records of the Family Planning Association of Uganda (FPAU) Mbarara branch clinic and with the assistance of their CommunityBased Reproductive Health Agents (CBRHA). The records of clients who had discontinued hormonal contraception were ascertained from this clinic. This was done by checking records for clients who had failed to return for their next scheduled appointment on two consecutive occasions. They were then reached by the address written in their records. Discontinuation of contraceptive use was further assured by confirming that the participants have not received hormonal contraception from other sources. All participants were between the ages of 22 and 44 years of age. All participants were literate and spoke English. This was an important consideration as English is one of the official languages of Uganda and the interviews had to be conducted in English. Meeting the criteria qualified the women to participate in the study. There were 17 participants who qualified and participated, with 15 of the 17 participants coming from the Banyankole ethnic group and two from the Baganda, the largest ethnic group in Uganda.

The study was explained and consent was obtained. The saturation point was reached after the seventeenth participant.

\section{Ethical Considerations}

The research was presented and approved by the Faculty Research and Ethics Committee and from the Institutional Ethical and Research Committee of Mbarara University of Science and Technology, Mbarara, Uganda. All participants signed a consent form to participate in the study. Confidentiality was assured by substituting code numbers for actual names as participant identifiers. All tape-recorded and transcribed data were stored in locked cabinets in one of the researcher's office. Only the researchers had access to the data.

\section{Rigor}

Credibility was established by ensuring participation only from those rural Ugandan women who had discontinued hormonal contraception according to the selection criteria. Furthermore, credibility was also assured through the validation of the formulated descriptions by the participants of the study, as required by Colaizzi's (1978) phenomenological approach. As with credibility, confirmability showed the way in which interpretations were arrived at via the inquiry interview (Koch, 1994). This was achieved by validation of formulated descriptions by the participants of the study. Guba and Lincoln (1989) argued that confirmability is established when credibility, transferability, and dependability are achieved.

Dependability was ensured by allowing for the process of data generation and analysis to be audited. This was evidenced by using audit trails and the verbatim descriptions by participants that illustrated the experience of having discontinued hormonal contraception. With these audit trails the researchers were able to lay bare the evidence from which the description of the lived experience was made.

\section{Results}

From the transcribed interviews, the researchers immersed themselves in the data by reading and rereading the transcriptions while listening to the audio-recorded interviews. While doing so, words, phrases, and statements that provided descriptions of the experience of discontinuing hormonal contraception were highlighted. From these highlighted data, themes were isolated and thematic categories were formulated to describe the experience. There were 12 themes isolated and four thematic categories were formulated. These thematic categories were Frustration and Helplessness, Living in Fear of Uncertainty, Ingenuity, and Accomplishments.

\section{Thematic Category 1: Frustration and Helplessness}

This thematic category was formulated based on the following two isolated themes:

- Dissatisfaction with contraceptive use

- Sadness and disappointment

Dissatisfaction with contraceptive use. The process of discontinuing hormonal contraception more often started with dissatisfaction in use. The women in this study went through a period of dissatisfaction. As stated by one respondent:

I started using Family Planning in 2000 with Norplant ${ }^{\circledR}$...I was fat but after two years I started to reduce without any cause. So when I went to the clinic I was explained to and told that Norplant can make you fat or small. So I decided to be patient and see how far I would go with it. But after some time I saw that I was getting finished, the thing was finishing me, my body was becoming smaller and smaller.

This dissatisfaction in use varied with the hormonal method being used, as can be seen in another respondent's experience:

I started using Family Planning injections after 6 months of delivering my first born. When time for going into periods came, I got my periods but stayed bleeding for a long time until I was due for the next injection, that's 3 months. I was told at the clinic that the bleeding was going to stop. Indeed it stopped 
immediately after the 2nd injection, but this was only for 1 week and then bleeding resumed until the next time for the 3rd injection...I stayed bleeding slowly for a whole year and I had little energy.

Some women continued using the method even with the discontent, because of the lack of better alternatives, as shown in the experience of this participant:

I first used pills but immediately after swallowing them I would experience abdominal pains. I would get dizzy and nauseated. I used pills for about 2 months but because of these side effects I stopped using them. I then started using injections... it gave me a lot of problems. But I just persevered because I didn't want to produce.

Sadness and disappointment. The lived experience of discontinuing hormonal contraception was also described as one of sadness and disappointment. Women were sad and disappointed because their goals of hormonal contraception were not met, as the following participant stated:

I felt bad after being disappointed by the method's failure to be compliant with my body. My goal of using Family Planning was not achieved because the methods have failed me and here I am scared of conceiving yet I don't want to add another family member.

For others the sadness and disappointment were attributed to side effects, as can be seen in the following participant's description:

When the baby was 1 year old, I decided to use pills. But they also disturbed me. I would get dizziness, lower abdominal pain, nausea, and

"Kuyoyayoya" [funny desires all the time]. I felt like vomiting all the time. So I got frustrated and decided to stay without any method.

For some women, the disappointment was also attributed to the failure of alterna- tive methods that they chose to use after discontinuing the hormonal ones, as the following two participants expressed:

When I abandoned the injection, I started to use the Kinyankole method...it involves the use of some dry seeds of a tree that are sown in a piece of cloth and then this cloth with the seeds is sown on someone's under garments, such as knickers or half petticoats, or on a small string that you can tie around the waist...so I used them for 4 months successfully, but now they have disappointed me because I am now pregnant; it seems they don't work.

Another participant described her experience as follows:

I had actually started using this method of withdrawal after my firstborn. But it disappointed me, because I became pregnant yet I didn't want to get pregnant because my first born was still young.

\section{Thematic Category 2: Living in Fear of Uncertainty}

This thematic category was formulated from the following three themes:

- Fear of becoming pregnant

- Having an unwanted pregnancy

- Fear of developing disease

Fear of becoming pregnant. The main reason women use contraceptives is to control when they conceive. So when they discontinue contraception, most often they end up living with the fear of becoming pregnant as the following three participants verbalized, "When I stopped using the injection and stayed without any contraceptive cover, I became well. But I continued meeting with my husbands sexually, so I was scared of becoming pregnant. I stayed in that mix for about 2 years."

"My goal of using Family Planning was not achieved because the methods have failed me and here I am scared of conceiving, yet I don't want to add another family member."

"Now the baby is 5 months old and I am not under any contraceptive cover. But I am scared because I am on a risk, I can conceive again any time and I don't want that. So I am confused."

Unwanted pregnancy. Women who discontinue contraception are the most likely to end up having an unwanted pregnancy. The following statement exemplifies this reality as one participant exclaimed, "We agreed with my husband that we just continue without any contraceptive cover and whatever comes out is what we shall have. This one soon disappointed us and I became pregnant after 3 months yet I didn't want it."

Similarly, another participant described her experience as follows, "Then about 2 months later before stabilizing, I again became pregnant. I hadn't wanted to conceive at this time because I was still weak."

For other women, the experience of discontinuing hormonal contraception has led them to acquire more than one unwanted pregnancy. The following two participants' experiences reveal this situation:

I had actually started using this method of withdrawal after my firstborn. But it disappointed me, because I became pregnant, yet I didn't want to get pregnant because my first born was still young... So we continued using the withdrawal method. Before the baby [second born] could reach 1 year I had again conceived by accident. I really hadn't planned for my third born but now I was already pregnant. I didn't want to become pregnant because my two children were still young. Conceiving again was totally not in our plan.

The other participant exclaimed that:

When the baby was one year old, I decided to use pills. But they also disturbed me...so I got frustrated and decided to stay without any method. In that time I conceived by accident and delivered my second born. So after de- 
livery I stayed without any method because I was breastfeeding. Time came and I could no longer breastfeed because he was now big. So we started using withdrawal method. But it became difficult for us. Then I again conceived by accident.

Fear of developing disease. The lived experience of discontinuing hormonal contraception among women in rural Uganda was also filled with the fear of developing disease. Women feared the effects of the specific method that they used, which were experienced in the form of physical symptoms that may lead to disease, as the following two participants believed, "I stopped using the injection because of fear that I might get problems of cancer or other diseases because I wasn't going into my periods...I was also fearing to develop pressure disease."

“The whole of 1987 I didn't get periods; so I feared that this might cause problems for me. So I left it and went on without any contraceptive cover."

\section{Thematic Category 3: Ingenuity}

The emergence of this thematic category was supported by the following five themes:

- Intermittent use of contraception

- Total discontinuity

- Use of less effective non-hormonal methods

- Use of unscientific methods

- No form of contraception at all

Intermittent use of contraception. The description of the lived experience of the respondents revealed that women were going through periods of intermittent use even with their preferred methods, as the experience of the following two participants show:

After producing, I started again on the contraceptives and I used the injection. But it gave me a lot of problems. I would get dizzy and wouldn't go into my periods. So I decided to use it and then rest from it. I decided to use it intermittently. I would use it then rest from it until I got my periods again. If I got my periods then I would restart it.

I stopped using the pill and started using the injection. But initially the injection was for stopping the bleeding. Surely it stopped the bleeding but again it also stopped me from going into my normal monthly periods. This happened for some good time and after that I was scared because I wasn't going into my periods. So I decided to use it intermittently. I would get the injection that lasts 3 months and in these 3 months I wouldn't get my periods. So I wouldn't go for another injection until I get my periods... But whenever it would come (my periods), the blood would be a lot, sometimes with clots. So then after the periods I would go for another injection. So it ended up that I would get only two injections a year, instead of the usual four. This lasted about 4 years.

Total discontinuity. Some women also chose to discontinue the hormonal contraceptive methods completely. This is usually because of the side effects of such methods, as shown by the following responses, "I spent the whole 2 years without periods. Then I stopped the injection. Now I stopped the injection and for the last 2 years I haven't used it and haven't used any contraceptive cover."

From the pills I then started using injections, I used it for 5 years. It also gave me a lot of problems. But I just persevered because I didn't want to produce. It made me lose appetite for sex, it would make me dry down there and when I would get my periods they would last a whole month and I would have a very stubborn headache all the time. So at the end of the 5 years I stopped using it. Now it's 1 year since I stopped it.
I had to make a decision between using the Family Planning, which was slowly killing me with those side effects, and not using, then I produce. So I chose to discontinue contraceptive use and I decided come what may. So I again conceived by accident and produced. Now the baby is 5 months old and I am not under any contraceptive cover.

Use of less effective non-hormonal methods. Some women who have discontinued hormonal contraception end up using less effective methods, as a participant put it, "But now that my periods were not coming, I was scared of conceiving again. I needed a method to use but didn't want the side effects. So we decided to use the withdrawal method (okuhereza ahansi)."

But since I was breastfeeding I knew I wouldn't conceive. So I insisted to continue breastfeeding. It helped me not to conceive again. But when the baby was $1 \frac{1}{2}$ years I had to stop breastfeeding. I could no longer breastfeed because he was now big. So we started using withdrawal method though it was difficult.

Use of unscientific methods. In the hopes of trying more effective methods, some women who have discontinued hormonal contraception shifted to using unscientific contraceptive methods, as the following participants expressed:

When I abandoned the injection, I started to use the kinyankole method...It involves the use of some dry seeds of a tree that are sown in a piece of cloth and then this cloth with the seeds is sown on the woman's under garments, knickers, or in a small cloth tied with a string that you can wrap around the waist.

"I tried to use the village herbs (omubazi gwe kyaaro) but the elders told me that it doesn't work, that you can become pregnant accidentally even when you are using then. But I know some women who use them." 
No form of contraception at all. The failure of and dissatisfaction from the methods they used led some women to completely abandon contraceptive methods. The statements below show how two participants no longer used any form of contraception:

I didn't feel well about the experience of discontinued use. I did not use any alternative method or solution after discontinuing the hormonal method; my husband and I agreed not to use any contraceptive method...

Then in 2004 I dropped off the injection because I could no longer stand the side effects. When I stopped using the injection and stayed without any contraceptive cover, I became well.

But I continued meeting with my husband sexually...

Other women are not using any contraceptive cover because they have interpreted the lack of periods to be a safe time for inability to conceive, as this participant stated:

Now I stopped the injection and for the last 2 years I haven't used it and haven't used any contraceptive cover. This is because I don't get my periods. So I know I cannot conceive even when I meet with my husband.

\section{Thematic Category Four: Accomplishments}

Two themes supported the thematic category of Accomplishments:

- Being normal again

- Fulfillment of being a wife, mother, and a woman

In discontinuing contraceptive use, women found a renewal of their self-worth, in being themselves again.

Being normal again. One theme extracted from the lived experience of the rural Ugandan women is the return to normalcy, as reflected in these statements, "For this time when I had stopped, I was well, the bleeding stopped, and then my periods be- came normal again" and "When I stopped using the injection and stayed without any contraceptive cover. I became well... and my periods returned."

Many women have contraceptive-induced amenorrhea and getting back the normal flow and arrival of periods is also considered a return to normalcy, as this participant stated, "I used the injection for a year and for that whole year I did not get my periods. So I stopped using it, for about 5 months. Then I got my periods and became normal."

Fulfillment of being a wife, mother, and a woman. The lived experience of discontinuing hormonal contraception among women in rural Uganda revealed a feeling of fulfillment of being a wife, mother, and a woman. As mothers, women have their roles to fulfill. Discontinuing contraceptive use enabled them to fulfill these roles, as two participants verbalized:

In the time before conceiving I was having a bad time with the injection. I was getting dizzy, a stubborn headache, I felt weak all the time, too much thirst all the time, and I couldn't do my work. After leaving the injection I became well and I could do my work.

But the pills made me too dizzy. Then I went to the village and was involved in a lot of work in the garden growing food and this worsened the dizziness...so I also stopped them. After some time I became well and the dizziness stopped so I could do my work.

Some women, as wives, expressed a concern for the quality of sexual intercourse that they and their husbands have, as this participant shared:

But the withdrawal method is also not easy for the man. I was having a bad time with the injection...I totally had no appetite for sex, it made me disgusted with my husband and I didn't even want to see him, it also made me dry in my private parts."

\section{Discussion}

Frustration and helplessness was one of the themes that emerged describing the lived experience of discontinuing hormonal contraception among women in rural Uganda. Frustration is defined as the feeling of being annoyed, upset, or impatient because you cannot control or change a situation or achieve something. Helplessness, on the other hand, is the inability to do anything to help oneself. This emerged from two categories: (a) dissatisfaction with use and (b) sadness and disappointment. The descriptions from the respondents revealed that the process of discontinuing hormonal contraception was typically associated with dissatisfaction with use of hormonal contraception. The women were frustrated because the hormonal contraception did not meet their set expectations. On the contrary, they were inconvenienced by the changes in menstruation and this was disappointing. For some women the change from one method to another did not help and this brought frustration. Because the women desired birth control and there was no other meaningful alternative, the women felt helpless. Some women persisted to continue using the method even with the discontent, only because of the lack of better alternatives, as shown in the experience of this participant:

I first used pills but immediately after swallowing them I would experience abdominal pains. I would get dizzy and nauseated. I used pills for about 2 months but because of these side effects I stopped using them. I then started using injections... it gave me a lot of problems. But I just persevered because I didn't want to produce...

Respondents revealed that this dissatisfaction led to frustration and helplessness, which in turn led to the discontinuation. This finding concurs with Ali and Cleland (1995) and Sadeghi-Bazargani et al. (2006) who concluded that women dissatisfied with their contraceptive methods led to their discontinuation of the contraceptive. 
Clearly, dissatisfaction with hormonal contraception is a real problem (Noone, 2004) and is associated with frustration and helplessness.

Living in fear of uncertainty emerged as another theme. Fear is an unpleasant feeling of being frightened or worried that something bad is going to happen while uncertainty is a feeling of not being sure or decided. Women feared that the method-related side effects that they experienced could lead to disease, as the following participant expressed, "I stopped using the injection because of fear that I might get problems of cancer or other diseases because I wasn't going into my periods...I was also fearing to develop pressure disease."

Women feared that the method-related side effects, especially the abnormal patterns in menstruation, could lead to disease. Women feared that blood from missed periods would build up inside their bodies and cause serious health problems or even infertility. For some of the women this was ground enough for discontinuation of the hormonal methods. Rutenberg and Watkins (1997) reported similar findings of women living in fear that was associated with developing a disease. Feared disease conditions were also similar and included fear of breast cancer, cervical cancer, and high blood pressure. Women lived in a state of uncertainty as they were not aware of what would befall them. Since some women had discontinued hormonal contraception and did not take up another effective method, yet continued to sexually meet their husbands while not wanting to conceive, they lived with an uncertainty of not knowing whether or when they would conceive an unwanted pregnancy.

Ingenuity is showing inventiveness and skill in developing a solution for a given challenge. Participants' descriptions revealed that hormonal contraception yielded challenges for the rural women, which enhanced their ingenuity. Women redesigned contraception protocols to best suit them.
For example, women in this study reported intermittent use of hormonal contraceptives in a bid to stay in "good health" as the experience of the following participant showed:

After giving birth I started again on the contraceptives and I used the injection. But it gave me a lot of problems. I would get dizzy and wouldn't go into my periods. So I decided to use it and then rest from it. I decided to use it intermittently. I would use it then rest from it until I got my periods again. If I got my periods then I would restart it.

Women reasoned that when they did not get their menstrual periods regularly, it was abnormal and was likely to cause health problems. So they would stop their hormonal contraception for some time until menstrual periods returned, before they would get their next supplies or injection. In this time of waiting for "normalcy" to return, they were not on any contraceptive because they reasoned that lack of menstrual periods meant they could not conceive. Unfortunately, this is not true and some mothers even conceived during this waiting time. Other ingenious practices included total discontinuity, use of less effective nonhormonal methods, and use of unscientific methods. It is important to know that others, ultimately, used no form of contraception at all. Noone (2004) and Peterson, Oakley, Potter, and Darroch (1998) also revealed that many women used hormonal contraceptives intermittently. Total discontinuity was also reported in the studies of Trussell and Vaughan (1999), Rosenberg et al. (1998), and Hardon (1997).

Accomplishment also emerged as a theme. Accomplishment is the act of finishing or achieving something good.

Accomplishment emerged from two categories: being normal again and fulfillment of being a wife, mother, and a woman.

Participants' descriptions revealed that the process of discontinuing hormonal contraception fostered a process of accomplishment through becoming normal and fulfillment of being a wife, mother, and a woman. Participants' descriptions revealed that women who discontinue hormonal contraception retrieve some measure of normalcy again. Many women who have developed contraceptive-induced amenorrhea consider the return of their regular menstrual periods as a return to normalcy and as a sense of accomplishment. This was because with the discontinuation, almost all the side effects ceased, hence, giving the women the opportunity to fulfill their roles as wives, mothers, and as women.

\section{Conclusion}

Isolated from the 12 themes and four thematic categories, the lived experience of discontinuing hormonal contraceptive use among women in rural Uganda is described as the frustration and helplessness of living in fear and uncertainty while enhancing the ingenuity of using other methods of contraception, thus fostering the accomplishment of being a wife, mother, and woman.

\section{Implications and Recommendations for Research, Education, and Practice}

Since discontinuing hormonal contraception is a major challenge facing women in rural Uganda, more specific healthcare attention should be provided to target women who are experiencing hormonal contraception challenges before they discontinue, and even after they discontinue, the use of contraceptives. There is the need for constant dispelling of myths held about hormonal contraception and other family planning methods. From this study it was found that lack of correct information and misconceptions foster inappropriate ingenuity, hence, hindering correct use of hormonal contraception methods. During the Family Planning counseling process, there is a need to include a session to dispel or clear the known misconceptions about contraceptives. This is due to the fact that a number of these known misconceptions are prevalent even among women who have gone through family planning counseling sessions, as revealed in the description of the lived experi-

\section{International Journal for Human Caring}


ence. Moreover, a session must be dedicated to providing correct information on the possible complications brought about by methods-related side effects. For example, heavy bleeding or long stretches of nonmenstruation can imply other abnormal physical conditions. These must be taken into account.

From the women's description of their experience, it was evident that most contraception discontinuation was related to the dissatisfaction and side effects of the hormonal methods. Therefore, there is a strong need for all stakeholders to venture into looking for workable and easily accessible solutions to the methods-related side effects.

External influences such as the influence of the husband are also real contributory factors to hormonal contraception discontinuation. There is consequently a need to have the male partner involved in the family planning counseling sessions.

Studies should be performed on the lived experience of discontinuing hormonal contraception among women in urban Uganda. This will enhance the understanding of the lived experience of the urban woman.

For the purpose of generalization there is a need to do a quantitative study with an instrument developed using the themes generated from this study. This can be done in a number of Ugandan districts because the experience of discontinuation may be different among other non-Banyankole ethnic groups because of cultural influences on sexual practices.

\section{References}

Affandi, B., Santoso, S.S.I., Djajadilaga,

Hadisaputra, W., Moeloek, F.A.,

Prihartono, J., Lubis, F. et al. (1987).

Five-year experience with Norplant.

Contraception, 36, 417-428.

Ali, M., \& Cleland, J. (1995). Contraceptive discontinuation in six developing countries: A cause-specific analysis.

International Family Planning
Perspectives, 21(3), 92-97.

Colaizzi, P.F. (1978). Psychological research as the phenomenologist views it. In R.S. Valle \& M. King (Eds.), Existential-phenomenological alternatives for psychology (pp. 48-71). New York, NY: Oxford University Press. Darroch, J.E., Landry, D.J., \& Oslak, S. (1999). Age differences between sexual partners in the United States. Family Planning Perspectives, 31, 160-167.

Guba, E.G., \& Lincoln, Y.S. (1989). Fourth generation evaluation. Newbury Park, CA: Sage.

Hardon, A.P. (1997). Women's views and experiences of hormonal contraceptives: What we know and what we need to find out. Reproductive Health Matters.

Retrieved from http://www.rhmjournal. org.uk/publications/beyond-acceptability/068_Hardon.pdf

Jarman, H., Kovacs, G.T., \& Westcott, M. (1990). Depo-Provera: A profile of current users. Australian and New Zealand Journal of Obstetrics and Gynecology, 30(1), 74-76.

Koch, T. (1994). Establishing rigor in qualitative research: The decision trail. Journal of Advanced Nursing, 19, 976986.

Noone, J. (2004). Finding the best fit: A grounded theory of contraceptive decision making in women. Nursing Forum, 39(4), 13-24.

Norwood, S.L. (2000). Research strategies for advanced practice nurses. Upper Saddle, NJ: Prentice Hall Health. Orem, D.E. (1995). Nursing concepts of practice (5th ed.). St. Louis, MO: Mosby. Ott, M.A., Adler, N.E., Millstein, S.G., Tschann, J.M., \& Ellen, J.M. (2002). The trade-off between hormonal contraceptives and condoms among adolescents. Perspectives on Sexual and Reproductive Health, 34(1), 6-14.

Peterson, L.S., Oakley, D., Potter L.S., \& Darroch, J.E. (1998). Women's efforts to prevent pregnancy: Consistency of oral contraceptive use. Family Planning
Perspectives, 30(1), 19-23.

Rosenberg, M.J., Burnhill, M.S., Waugh, M.S., Grimes, D.A., \& Hillard, P.J. (1998). Compliance and oral contraceptives: A review. Contraception, 52, $137-$ 141.

Rutenberg, N., \& Watkins S.C. (1997). The buzz outside the clinics: Conversations and contraception in Nyanza Province, Kenya. Studies in Family Planning, 28, 290-307.

Sadeghi-Bazargani, H., Ehdaeivand, F., Arshi, S., Eftekhar, H., Sezavar, H., \& Amanati, L. (2006). Low-dose oral contraceptive to re-induce menstrual bleeding in amenorrheic women on DMPA treatment: A randomized clinical trial. Medical Science Monitor, 12, 420-425.

Taylor, S.G. (2006). Dorothea E. Orem: Self-care deficit theory of nursing. In A.M. Tomey \& M.R. Alligood (Eds.), Nursing theorists and their work (pp. 267-296). St. Louis, MO: Mosby.

Trussell, J., \& Vaughan, B. (1999). Contraceptive failure, method-related discontinuation and resumption of use: Results from the 1995 national survey of family growth. Family Planning

Perspectives, 31(2), 64-72.

Uganda Bureau of Statistics. (2001). The 2000-2001 Uganda demographic and health survey (UDHS): A nationally representative survey of households and of women age 15-49 and men age 15-54. Calnerton, MD: ORC Macro.

Uganda Bureau of Statistics. (2003). The 2002 Uganda population and housing census. Retrieved from http://www.ubos. org/onlinefiles/uploads/ubos/pdf\%20documents/2002\%20CensusGenderAnalytic alReport.pdf

Uganda Delivery of Improved Services for Health. (2001). Literature review on the relationship between discontinuation rates and fertility. Retrieved from http://www.ugandadish.org/resources/lit.s html

Westfall, J.M., Main, D.S., \& Barnard, L. (1996). Continuation rates among in- 
jectable contraceptives. Family Planning

Perspectives, 28, 275-77.

Wu, J., Wang, L., Rauyajin, O., \& Good, S. (2002). Contraceptive use behavior among never married young women who are seeking pregnancy termination in Beijing. Chinese Medical Journal, 115, 851-855.

\section{Author Note}

Joseph Mwizerwa, Head of Department of Nursing, Aga Khan University, Kakmpala, Uganda and Rozzano C. Locsin, John F. Wymer Distinguished Professor of Nursing, Florida Atlantic University. Christine E. Lynn College of Nursing, Boca Raton, Florida.

Correspondence concerning this article should be sent via Internet to mwizjoe@yahoo.com

The authors wish to express appreciation for the support provided by Mbarara University of Science and Technology for partially funding of the research study and the International Association for Human Caring (IAHC) for providing the support through the Droesbeke Award for the lead researcher to present the study to participants during the IAHC conference in St. Louis, Missouri, in 2007.

The authors would like to acknowledge, with gratitude, all the participants of the study and the contributions of Dr. Charlotte Barry and Dr. Marilyn Parker, thesis panel members, and Ms. Geliah Gloria who provided editorial expertise.

\section{International Journal for Human Caring}


Copyright of International Journal for Human Caring is the property of International Association for Human Caring and its content may not be copied or emailed to multiple sites or posted to a listserv without the copyright holder's express written permission. However, users may print, download, or email articles for individual use. 